\title{
The Performance of Lightning Rod Arrester and Its Effect on the Top Potential of Tower for $500 \mathrm{kV}$ Transmission System
}

\author{
Jian'gang Gong1, Zhouyou Lin², Yangyong Xu${ }^{1}$, Shen Zhao², Qiang Zhang ${ }^{3}$ \\ ${ }^{1}$ State Grid Zhejiang Electric Power Company, Hangzhou, China \\ ${ }^{2}$ Wenzhou Power Supply Company of State Grid Zhejiang Electric Power Company, Wenzhou, China \\ ${ }^{3}$ Chengdu Xinghe Technology Industry Corporation, LTD, Chengdu, China \\ Email: 22574193@qq.com
}

Received 12 September 2014; revised 25 October 2014; accepted 14 November 2014

Copyright (C) 2014 by authors and Scientific Research Publishing Inc.

This work is licensed under the Creative Commons Attribution International License (CC BY).

http://creativecommons.org/licenses/by/4.0/

(c) (i) Open Access

\begin{abstract}
When the tower overhead is struck by the lightning impulse, the lightning current flows into the earth through the impedance of tower and the grounding resistance, which heightens potential of the tower overhead and possibly induces insulator flashover. Lighting rod arrester is used to shield the tower and provide another routine for lightning current, decreasing the potential of tower overhead. In this paper, the performance of a $500 \mathrm{kV}$ lighting rod arrester is tested used in AC transmission system under the current impulse. Besides, the influence of the lightning rod arrester performance on the top potential of tower is also studied. The results show that, when the rod arrester is connected to the tower, the top potential of tower can be obviously limited under the lightning strike.
\end{abstract}

\section{Keywords}

Lightning Impulse, Grounding Resistance, Lightning Rod, Top Potential of Tower, Insulator Flashover, Lightning Protection

\section{Introduction}

With the incessant increase of social electrical power demands, more and more Extra-High Voltage (EHV) and Ultra-High Voltage (UHV) AC/DC power transmission lines are under planning and construction. Because the energy supply entered in China is far away from the power load district, the transmission line corridors are unavoidably through the regions with the complex terrain, including the mountains with frequent lightning activi- 
ties [1]-[5]. Once the lightning impulse strikes the tower overhead, the lightning current flows into the earth through the impedance of the tower and the grounding resistance, which heightens the potential of the tower overhead and possibly induces insulator flashover. When the lightning rod arrester is installed on the tower overhead, it can shield the electric field of the tower overhead and can provide another routine for the lightning current, which directly limits the potential of tower overhead and protects the safety of insulator [6]-[8].

In $500 \mathrm{kV}$ AC transmission system, a large number of lightning rod arresters have been used to protect the transmission line. To guarantee the stability and reliability of the lightning rod arresters, the performance test of the lightning rod under pulsed current waveform is necessary. Besides, when the lightning current flows through the lightning rod connected by the down lead, the potential of the tower overhead will also change. With different connection method of the lightning rod, the potential of tower overhead varies. Thus, it is also important to investigate the connection method of the lightning rod.

In this paper, the performance test of the $500 \mathrm{kV}$ lightning rod arrester under current impulse is conducted. Besides, the potential of the tower overhead is tested when the lightning rod is installed in a $500 \mathrm{kV}$ tower and connected to the center of the tower by the down lead while different current waveform is applied.

\section{Property Test under Lightning Current Impulse}

To obtain a current impulse with variable rise time and duration, a capacitor bank, including six $30 \mathrm{kV} 8 \mu \mathrm{F}$ capacitors and equipped with a resistor and inductance to adjust the waveform, is employed. The schematic diagram of the discharge circuit and the picture of the $500 \mathrm{kV}$ lightning rod are shown in Figure 1. The current of the discharge circuit is measured by a Rogowski Coil (Pearson 101, $4 \mathrm{MHz}, 50 \mathrm{kA}$ ) while the voltage on the lightning rod is monitored by a High Voltage Probe (Tek-6015A, $75 \mathrm{MHz}, 40 \mathrm{kV}$ ).

When six capacitors are connected parallel to each other and discharge to the lightning rod, both the current and voltage waveforms with different charged voltage $U$, are measured and shown in Figure 2 . The current is with a rise time $(10 \%-90 \%)$ of $17 \mu$ s and a duration (full width at half maximum, FWHM) of $40 \mu \mathrm{s}$. Due to the high inductance of the lightning rod arrestor, the voltage waveform of lightning rod under current impulse has an overshoot, as shown in Figure 2(b). Both the overshoot $U_{\mathrm{o}}$ and the peak $U_{\mathrm{p}}$ of the waveform platform are recorded and shown in Figure 2(c).

With a fixed charged voltage of $17.5 \mathrm{kV}$, different capacitor is used to generate the current waveforms with different rise time and duration. Five kinds of current waveforms are generated, and the waveform parameters are 17.4/39.6, 15.2/36.6 s, 14/32.6, 13.1/28.9 and 9.7/25.1 $\mu$ s respectively. Under the current waveforms, the voltage waveforms are monitored and shown in Figure 3.

\section{The Effect of Lightning Rod Arrester on the Top Potential of Tower}

To study the effect of lightning rod on the potential of tower, the lightning rod is installed on the top of an actual $500 \mathrm{kV}$ tower, as shown in Figure 4. The bottom of the lightning rod is fixed by an insulated support and connected to the center of the tower by a down lead while the top of lightning rod is directly connected to the current pulse generator for current injection. The current waveform produced by the current generator has two sets

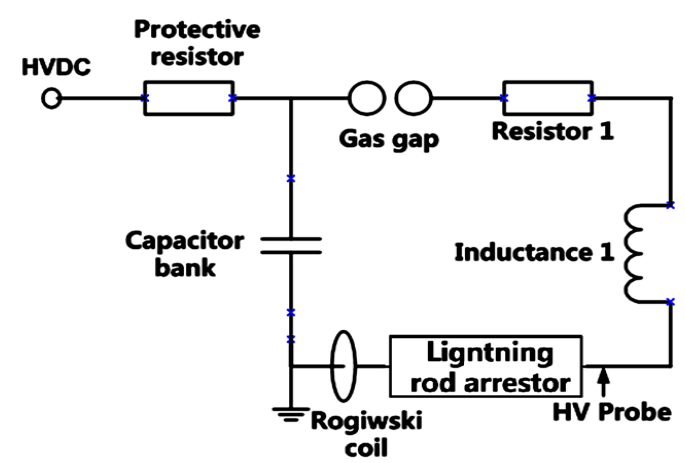

(a)

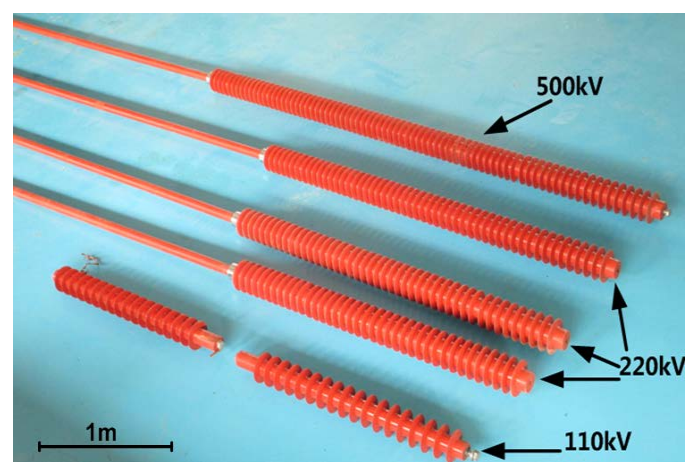

(b)

Figure 1. The schematic of the test circuit and the picture of lightning rod arresters. (a) test circuit; (b) lightning rod arresters. 


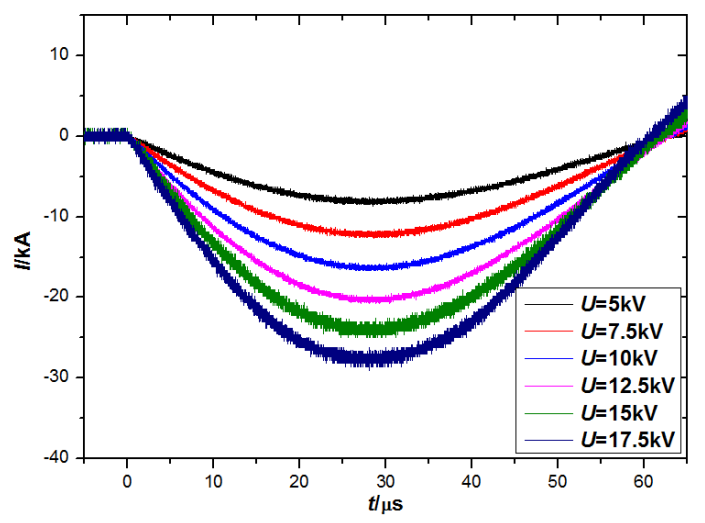

(a)

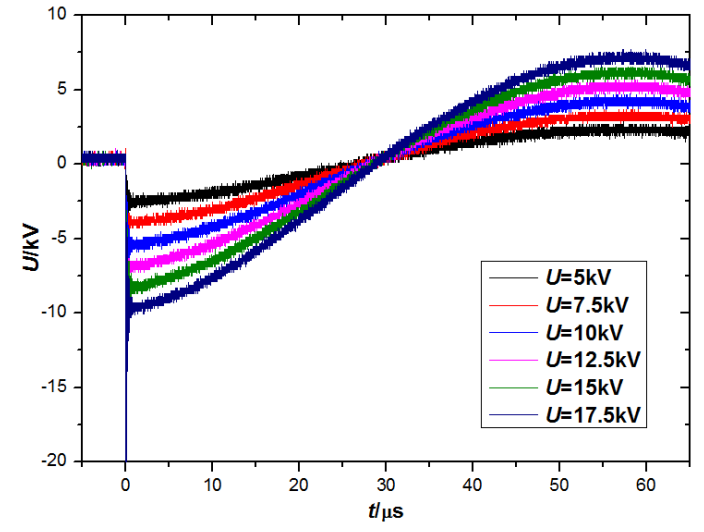

(b)

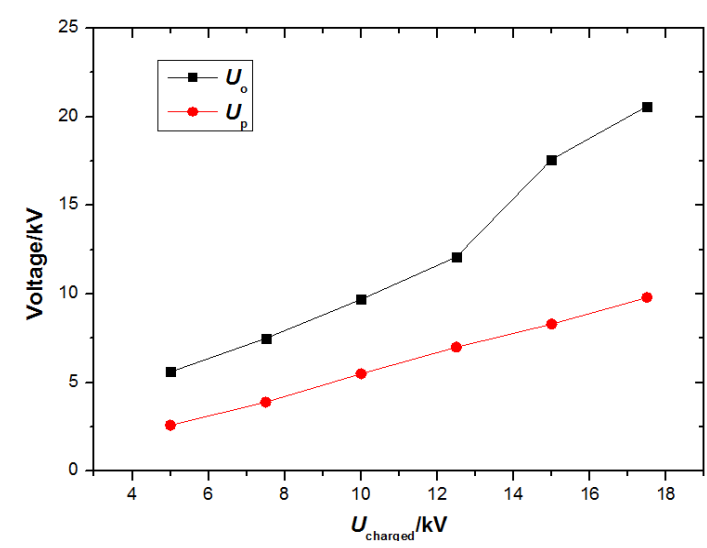

(c)

Figure 2. Current and voltage waveforms with different charged voltage. (a) current waveform; (b) voltage waveform; (c) the overshoot and peak of voltage waveform.

Table 1. The current parameter and potentials in different locations.

\begin{tabular}{ccccccc}
\hline Applied current & $I_{\text {peak }}(\mathrm{kA})$ & Rise time $(\mu \mathrm{s})$ & FWHM $(\mu \mathrm{s})$ & $U_{1}(\mathrm{kV})$ & $U_{2}(\mathrm{kV})$ & $U_{3}(\mathrm{kV})$ \\
\hline $4 / 10 \mu \mathrm{s}$ & 18.42 & 15.3 & 34.5 & 17.6 & 5.2 & 5.3 \\
$8 / 20 \mu \mathrm{s}$ & 17.24 & 17.5 & 38.5 & 13.6 & 4.2 & 4.4 \\
\hline
\end{tabular}

of parameters, $4 / 10 \mu$ s and $8 / 20 \mu$ s respectively. When the current is applied to the lightning rod, the potential of three points, including the top of the lightning rod and both the top and center of the tower, are measured. The equivalent circuit is shown in Figure 4(b). The current waveform and the potentials in different locations are recorded and shown in Table 1.

According to the data in Table 1, the potential of the top of the lightning rod is far higher than that of the overhead of the tower, and most of the voltage are applied to the lightning rod and the down lead. Under both current waveform, the potentials in different locations have the similar trend. In this way, the potential of the tower overhead can be greatly limited by the lightning rod, which can directly decrease the voltage on the insulator and reduce the probability of insulator flashover.

\section{Conclusion}

In this paper, the performance of the $500 \mathrm{kV}$ lightning rod under lightning current impulse is studied. Besides, when the lightning rod arrester is installed in a $500 \mathrm{kV}$ tower and connected to the center of the tower, the potential of different locations is investigated. When the lightning current impulse flows through the lightning rod, the rise time and duration of current waveform increase and an overshoot will be generated on the lightning rod. Once the lightning strikes the lightning rod, the current will flow through the down lead and greatly limit the 


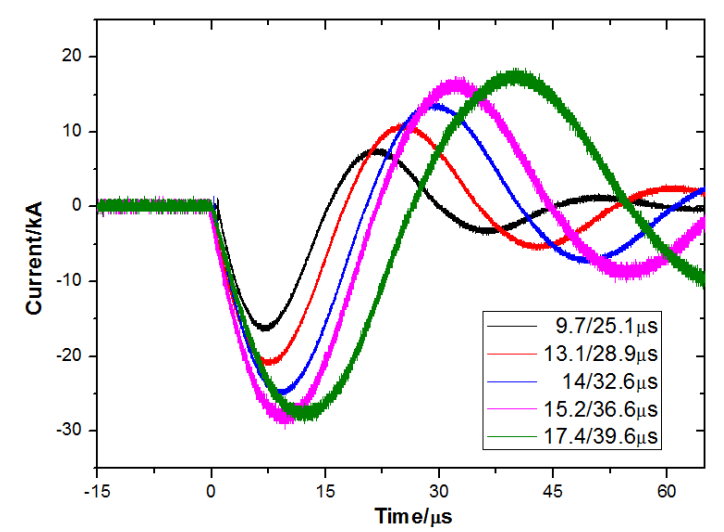

(a)

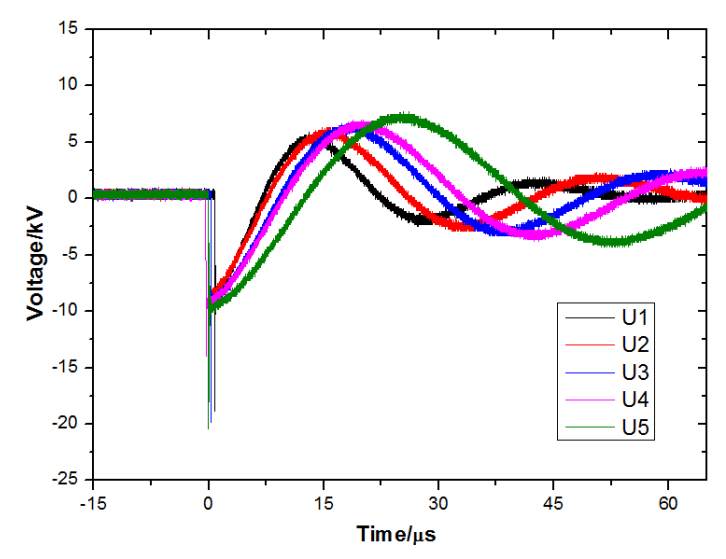

(b)

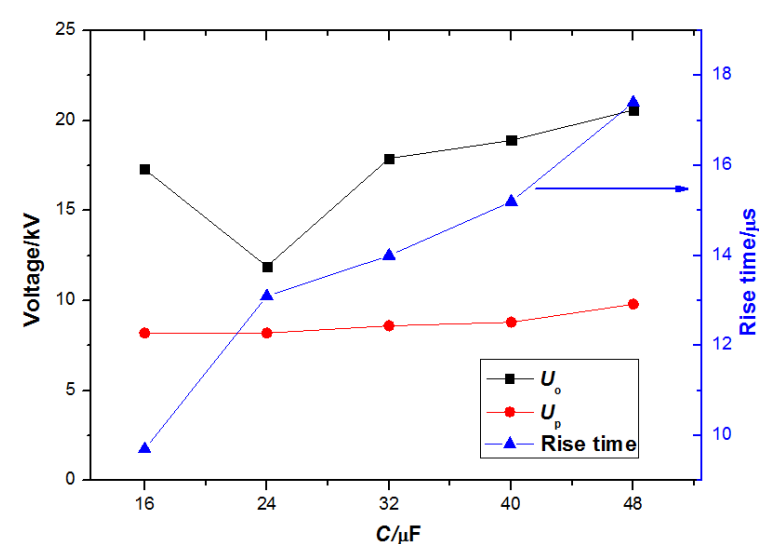

(c)

Figure 3. Current and voltage waveforms under different waveforms. (a) current waveform; (b) voltage waveform; (c) the overshoot and peak of voltage waveform.

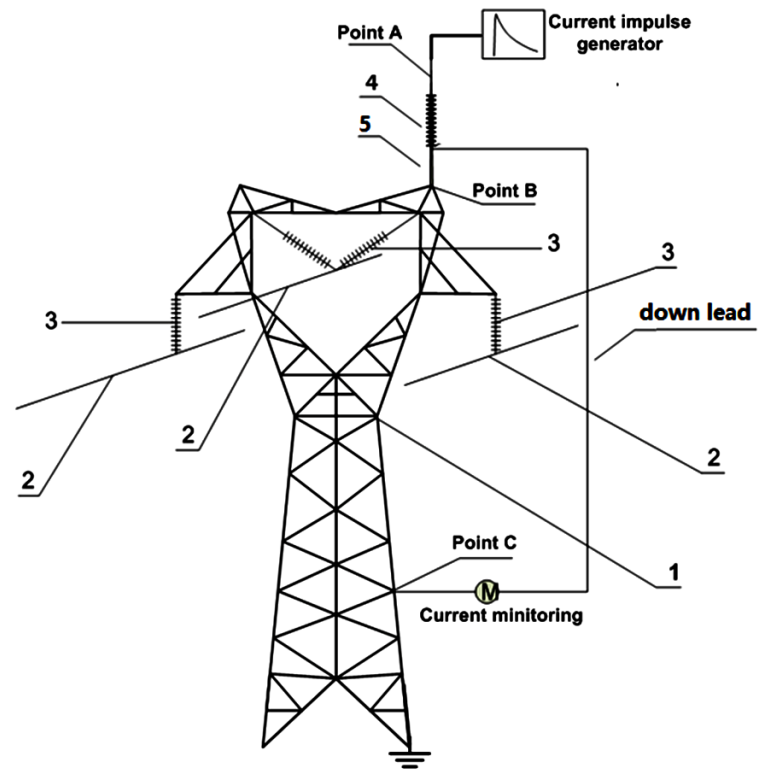

(a)

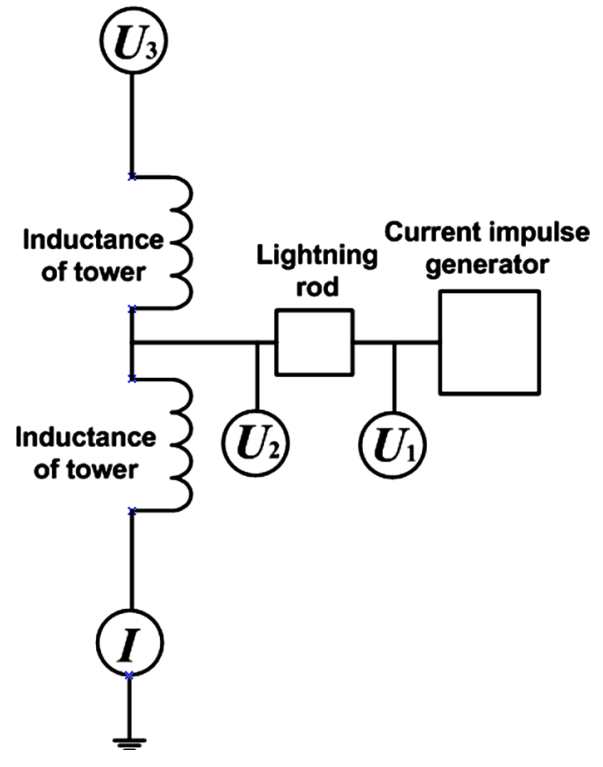

(b)

Figure 4. The test circuit (1-the tower; 2-transmission lines; 3-the insulators; 4-the lightning rod; 5-the insulated support). (a) the $500 \mathrm{kV}$ tower; (b) the equivalent circuit. 
potential of the tower overhead. In the future research, investigating the influence of connection method of lightning rod on the potential of tower overhead would be the main focus.

\section{References}

[1] Wu, J.R. and Xu, Y.X. (2005) Development Prospect of UHV AC Power Transmission in China. Power System Technology, 29, 1-4.

[2] Zhang, W.L., Wu, W.N. and Hu, Y. (2003) Research on UHV Transmission Technology and Development of Power Network in China. High Voltage Engineering, 29, 16-18.

[3] Zheng, J.C. (1995) On the Alternatives for the Next Voltage Level of AC Power Transmission. Power System Technology, 19, 3-8.

[4] Xiang, L.R. (1996) Speed up Earlier UHV Transmission Research in China. Power System Technology, 20, 54-58.

[5] Zhu, M.H. (2000) Energy Resources, Integrated Interconnection Network, UHV Transmission. High Voltage Engineering, 26, 28-30.

[6] Furukawa, S., Usuda, O., Isozaki, T., et al. (1989) Development and Application of Lightning Arresters for Transmission Lines. IEEE Transactions on Power Delivery, 4, 2121-2129. http://dx.doi.org/10.1109/61.35639

[7] Wei, L.X. and Wu, W.H. (1998) The Analysis of Lightning Protection for EHV and UHV Transmission Lines in Russia. High Voltage Engineering, 24, 76-79.

[8] He, J.L., Zeng, R. and Chen, S.M. (2009) Lightning Protection Study of Transmission Line, Part III-Protection Measures. High Voltage Engineering, 35, 2917-2923. 
Scientific Research Publishing (SCIRP) is one of the largest Open Access journal publishers. It is currently publishing more than 200 open access, online, peer-reviewed journals covering a wide range of academic disciplines. SCIRP serves the worldwide academic communities and contributes to the progress and application of science with its publication.

Other selected journals from SCIRP are listed as below. Submit your manuscript to us via either submit@scirp.org or Online Submission Portal.
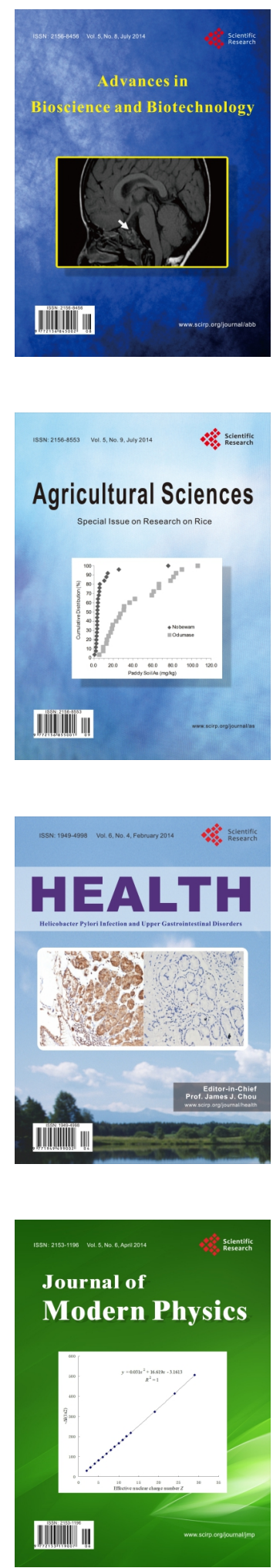
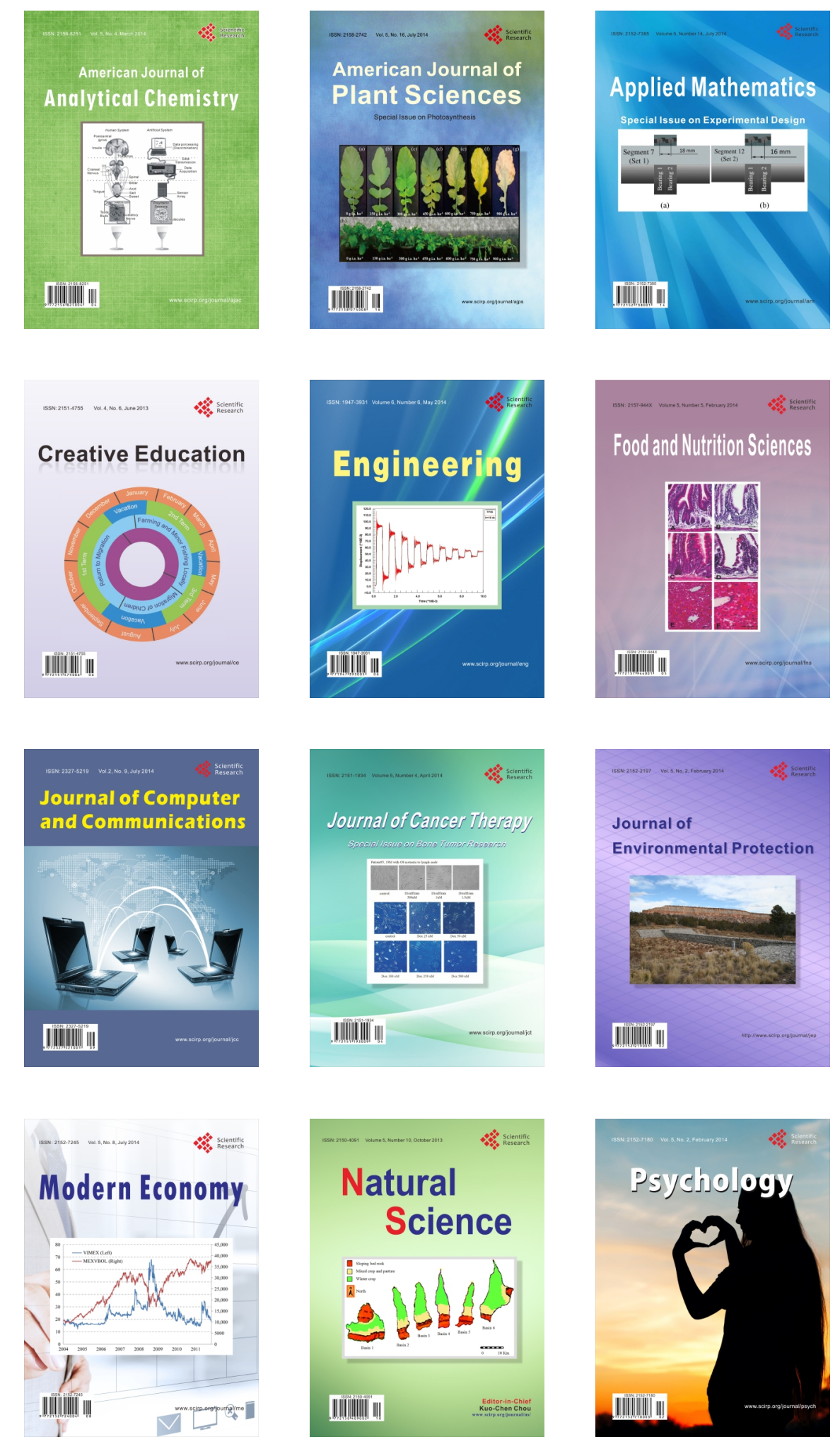